Prof. K. H. Schleifer

Lehrstuhl für Mikrobiologie

Universität München

Menzinger Strasse 67

D-8 München 19, BRD
Prof. D. A. A. Mossel

Institute of Food Science

Faculty of Veterinary Sciences

Bilstraat 172

Utrecht, Holland

\title{
Report (1970-1974) of the Subcommittee on Phage-Typing of Staphylococci to the International Committee on Systematic Bacteriology
}

\author{
26 September 1974
}

Brno, Czechoslovakia

This report describes the work of the Subcommittee during the years 1970 through 1974 and includes a summary of the decisions taken at the Sixth Meeting, which was held in Brno, Czechoslovakia, on 26 September 1974 .

1. Membership and officers. The Subcommittee consists of a Chairman, a Secretary, 52 representatives of national staphylococcal phage-typing laboratories, and two co-opted members. The full list of the present membership is as follows: D. S. Agarwal, New Delhi, India; A. Akatov, Moscow, USSR; A. Alaoui, Rabat, Morocco; F. Al-Rawi, Baghdad, Iraq; L. Arcalis, Barcelona, Spain; E. Asheshov, London, England (Secretary); J. L. Avril, Algiers, Algeria; J. Beumer, Brussels, Belgium; J. Borst, Utrecht, Netherlands; H. Brandis, Bonn, Germany (FR); R. Cassel, Johannesburg, S. Africa; E. T. Cetin, Istanbul, Turkey; X. Chang, Chendu, Szechwan, China; C. H. Chang-Teoh, Hong Kong; Vu Qui Dai, Saigon, South Vietnam; I. Davidson, Weybridge, England; Doki Chun, Taegu, Republic of Korea; Y. A. El Batawi, Cairo, Egypt; H. Erwa, Khartoum, Sudan; J.-M. Fouace, Paris, France; T. H. Fuh, Taipei, Taiwan; R. Gharagozloo, Teheran, Iran; M. Grigorova, Sofia, Bulgaria; I. G. T. Hettiaratchy, Colombo, Sri Lanka; A. W. Jackson, Ottawa, Canada; S. Kryński, Gdánsk, Poland; C. Lamjav, Ulan Bator, Mongolia; A. M. Marquez, Montevideo, Uruguay; V. Mátejovska, Prague, Czechoslovakia; W. Meyer, Wernigerode, Germany (DDR); H. Milch, Budapest, Hungary; S. Mitsuhashi, Maebashi, Japan; M. Moreira-Jacob, Lisbon, Portugal; P. Oeding, Bergen, Norway; V. Ortali, Rome, Italy; M. T. Parker, London, England; M. Popovici, Bucharest, Roumania; I. Rantasalo, Helsinki, Finland; H. Reber, Basel, Switzerland; H. Rische, Wernigerode, Germany (DDR); R. A. Robinson, Wellington, New Zealand; M. Rodriguez-Leiva, Santiago, Chile; K. Rosendal, Copenhagen, Denmark; M. Rotter, Vienna, Austria; P. M. Rountree, Sydney, Australia (Chairman); C. A. Salles, Accra, Ghana; L. E. Sanchez-Torres, Mexico City, Mexico; L. S. Saubert de Allegroni, BuenosAires, Argentina; L. Sjöberg, Stockholm, Sweden; R. Skalova, Zagreb, Yugoslavia; P. Byrd Smith, Atlanta, Georgia, USA; C. Solé-Vernin, Sao Paulo,
Brasil; D. Sompolinsky, Tel Aviv, Israel; K. Win, Rangoon, Burma; B. Wimsley, Dar-es-Salaam, Tanzania.

The Staphylococcus Reference Laboratory at the Central Public Health Laboratory, Colindale, London NW9 5HT, England is designated the WHO Collaborating Centre for Reference and Research on Staphy. lococcal Infections and acts as the International Centre for Staphylococcal Phage-Typing.

2. International standardization. At intervals of 4 years, the International Centre distributes fresh stocks of the typing phages and their propagating strains to each national laboratory. The phage stocks are usually issued as freeze-dried high-titre preparations which should, on reconstitution, provide sufficient material for one large-scale propagation and still leave enough material to provide a reference standard for the lytic spectrum of the locally prepared phage.

Since 1952, international comparative typing tests have been carried out every 4 years. Twenty-five strains are sent to each national laboratory that wishes to take part in the test, with a request that the strains be typed both at RTD and RTD $\times 100$ with the laboratory's current phage preparations. The results are analysed and a report is sent to each national laboratory.

The results of the two most recent tests, carried out in 1969 and 1973, showed that deviations in the typing patterns of the test strains in the different laboratories were small and most easily explained as being due to differences in the media used for typing rather than to differences in the specificity of the phages. This suggests that standardization of medium would be desirable. However, because the most important variable in the medium appears to be the type of agar used, and there is a world-wide shortage of agar, it is not considered possible at the present time to recommend a standard medium that could be made in all countries. However, it is recommended that, wherever possible, a single standard medium be used in each individual country.

3. Strength of phages for typing. It is the normal practice to type strains of Staphylococcus aureus first with the phages diluted to RTD (routine test dilution) and to retype strains that are untypable with the 
phages at a 100 times stronger concentration (RTD $\times$ $100)$. However, the three most recent additions to the basic set, phages $83 \mathrm{~A}, 84$, and 85 , are used only at RTD and not at the stronger concentration (2). A report submitted by Dr. K. Rosendal of Denmark to the Sixth Meeting of the Subcommittee showed that this results in a loss of typability with certain strains and often makes the recognition of epidemiologically related strains difficult. It was therefore agreed that this practice should cease; in the future, all phages now in the basic set and any phages added to the set will be used at both concentrations.

4. Typability of strains of $S$. aureus. The percentage of strains of $S$. aureus susceptible to lysis by the phages in the current basic set has declined in recent years (3). An analysis carried out at the International Centre in 1972 of strains isolated in Great Britain between the years 1966 and 1972 showed that: (i) the over-all typability of strains had dropped from 88 to $90 \%$ in 1966 to about $75 \%$ in 1972 ; and (ii) the percentage of strains typable at RTD had dropped during the same interval from 75 to just over $50 \%$. This time interval covered the period when the change was made from typing at RTD $\times 1,000$ to RTD $\times 100$, but the evidence suggested that this change in method was not responsible for the loss in typability observed in Britain.

To ascertain how general this loss in typability was, requests were sent to all national laboratories to provide similar information on the typability of the strains that they were encountering. Thirteen laboratories complied with this request. Loss of typability similar to that found in Great Britain was reported from the United States, Denmark, France, Finland, and East Germany and, to a lesser extent, from Sweden, but not from Canada, Belgium, West Germany, Hungary, Australian, New Zealand, or Yugoslavia. In Denmark, and possibly in Finland, there was some indication that loss of typability was due to the change from typing at RTD $\times 1,000$ to RTD $\times 100$. However, in the other five countries, the decrease in the percentage of typable strains could not be attributed to this cause because the percentage of strains typable with the stronger phage concentration, whether at RTD $\times 1,000$ or at RTD $\times 100$, remained about the same. It was concluded that, in most countries in which a decrease in typability was observed, this reflected a general increase in the number of strains that were resistant to lysis by the phages in the current basic set.

5. Modifications of the basic set of typing phages. Of seven experimental phages examined at the International Centre in the years 1970 through 1974, three appeared to be useful in typing otherwise untypable strains of staphylococci. These were as follows: phage WH-1 (official number 94), isolated by L. Blouse, United States (1); and phages DU-1 (official number 95) and DU-2 (official number 96), isolated by J. Markham, New Zealand. In 1971 through 1972, these three phages were issued to all national laboratories for evaluation. At the same time, it was suggested that four other experimental phages, numbers $88,89,90$, and $92(3)$, be reexamined as potentially useful typing phages.

Reports received from 19 laboratories on the activity of these seven phages showed clearly that phages 94,95 , and 96 were of value in most countries in lysing otherwise untypable strains. Results with phages 88 , 89 , and 90 confirmed an earlier impression (3) that they are useful in certain countries but not of sufficient general value to merit their addition to the basic set. Phage 92, although apparently valuable in typing untypable strains, proved to be too nonspecific in its range of activity. It lysed $33.7 \%$ of all strains tested in Great Britain and $41.7 \%$ of all strains in Denmark.

It was agreed at the Sixth Meeting of the Subcommittee that phages 94,95 , and 96 should be added to the basic set. Phages 94 and 96 often lyse the same strains, but in a number of countries strains lysed by only one of the two phages appear to be fairly common. It was further agreed that phages 88,89 , and 90 should not be added to the set but should be maintained as additional phages in those countries in which their use decreased significantly the percentage of untypable strains. Phage $42 \mathrm{D}$ and 187 were removed from the basic set.

The current basic set consists of 23 phages as follows: group I, numbers $29,52,52 \mathrm{~A}, 79$, and 80 ; group II, numbers $3 \mathrm{~A}, 3 \mathrm{C}, 55$, and 71 ; group III, numbers 6 , $42 \mathrm{E}, 47,53,54,75,77,83 \mathrm{~A}, 84$, and 85 ; not allocated: numbers $81,94,95$, and 96 .

\section{LITERATURE CITED}

1. Blouse, L. E., W. B., Stringfield, R. V. Marraro, and H. J. Dupy. 1973. Proc. Soc. Exp. Biol. Med. 142:572.

2. International Committee on Nomenclature of Bacteria. Subcommittee on Phage-Typing of Staphylococci. 1967. Report of the meeting, 22 July 1966, Moscow, USSR. Int. J. Syst. Bacteriol. 17:113-125.

3. International Committee on Nomenclature of Bacteria Subcommittee on the Phage-Typing of Staphylococci 1971. Minutes of the Meeting, 6 August 1970, Mexico City, Mexico. Int. J. Syst. Bacteriol. 121:165-166.

Elizabeth H. Asheshov, Secretary Phyllis M. Rountree, Chairman 